\title{
The Path to Select Chinese Progressive Delay Retirement Age Policy
}

\author{
Ren Fan $^{1}$ \\ ${ }^{1}$ School of Management, Shanghai University of Engineering Science, Shanghai, China
}

Correspondence: Ren Fan, Shanghai University of Engineering Science, Shanghai, China. E-mail: glxyrf2014@163.com

Received: May 19, 2015 Accepted: June 5, 2015 Online Published: July 2, 2015

doi:10.5430/sass.v2n2p19 URL: http://dx.doi.org/10.5430/sass.v2n2p19

\begin{abstract}
The development of society and the improvement of living standards make our life expectancy extended gradually that constantly accelerate the process of our country into aging society. With the degree of aging becoming deeper, endowment the insurance financial risk and the pension gap increases gradually, so we must speed up the analysis of the policy about delay retirement age. The policies with delay retirement age choose way of incremental reform in China. First of all, the policy has many feasible ways: First, the policy can help alleviate the pressure of the pension payment. Second, some elder have the ability to work continuously. Last but not least, the policy can also promote the stable development of gradual reform. At the same time, the policy of gradual delay retirement age in China has some controversies and difficulties: first some people think delay retirement will cause the extrusion effect. Second, the policy maybe have influence on the productivity of social labor. Third, some people rather go on working than delay because the wages is lower than pensions a lot. Forth, abnormal sense of labor makes some people do not want to continue to work. For the advancement of Chinese incremental delay retirement age policy, we can choose next ways: First, we can choose some appropriate propaganda ways and gradually advanced delay retirement. Second, we must make up the standard of pension and the specific plan scientifically. The last, we can set up the incentive mechanism to encourage delay retirement.
\end{abstract}

Keywords: progressive, Delay retirement age, Controversy The path selection

\section{Introduction}

Social security as an important policy arrangement of building a harmonious society, its importance is self-evident. In the research of social security, the delay retirement age is an important research subject. With the deepening of Chinese aging population level, the system of financial sustainability has challenged and the pension gap appearing constantly expanding, this makes the delay retirement age have to be on the agenda. Adopted the policy of gradual delay retirement age is the way that accepted by both politics and academia, but how to implement this policy is still controversial, so it has important practical significance to choose a suitable path for incremental delay retirement age policy path.

\section{Pursuing a Policy of Gradual Delay Retirement Age}

Delay retirement age involves the interests of various social groups, different social groups about whether this policy can imply successfully also have different opinions. So it is necessary to analyze the feasibility of incremental delay retirement age policy aimed at the hot topic in the current society.

\subsection{The Current Situation of the Development of Chinese Population Age Structure}

According to the Bureau of statistics data, China elderly population over the age of 60 accounted for the total number of more and more big, the elderly dependency ratio increased year by year, the average life expectancy is also growing. Therefore, China being accelerated in aging society. However, with the widespread growth in population, the people's physical health index is rising year by year, a lot of old people even reach retirement age, but still has the work enthusiasm and ability. So, let the healthy people go home in this time will have a bad effect on economic development. 
Table 1. The distribution table of the average life expectancy in China population age

\begin{tabular}{l|llll} 
Number & years & mean age & mean age (male) & mean age (female) \\
\hline 1 & 1982 & 66.77 & 66.28 & 69.27 \\
2 & 1990 & 68.55 & 66.84 & 70.47 \\
3 & 2000 & 71.40 & 69.63 & 73.33 \\
4 & 2010 & 74.83 & 72.38 & 77.37
\end{tabular}

Table 2. 60-74 age distribution table of the year 2012

\begin{tabular}{l|lllll} 
Number & Age & $\begin{array}{l}\text { People } \\
\text { number }\end{array}$ & proportion (\%) & $\begin{array}{l}\text { Male } \\
\text { (million) }\end{array}$ & $\begin{array}{l}\text { Female } \\
\text { (million) }\end{array}$ \\
\hline 1 & $60-64$ & 55427 & 4.93 & 27928 & 27499 \\
2 & $65-69$ & 37579 & 3.34 & 18728 & 18851 \\
3 & $70-74$ & 28225 & 2.51 & 13991 & 14234
\end{tabular}

The 1-2 shows that although Chinese statutory retirement age for men is 60 years, women is 50 years. But whether it is male or female, the age is in constant growth constantly (Figure 1), 60-64 years old accounted for $4.93 \%$ of the total population (Figure 2), this is a very large numbers, these people actually still has the working conditions. China is also in the aging society even if the definition for elderly people is over the 65 years. Therefore, judging from China's population situation, China urgently needs to promote retirement age policy.

\subsection{A Large Part of the Old People Still Have the Ability to Continue to Work}

Due to the development of the family planning policy, the social group structure gradually changed, and the proportion of elderly in the total population is bigger and bigger, so that the "monumental exploits and life pressure is more and more big, under the condition of better social life level, the average age population is increasing, many old people as career and still full of enthusiasm but to face the plight of the retirement. Long-term free after retirement will add to the loneliness of the elderly, in the long run, most elderly people produce the desire about back to continue work. So, a large part of the elderly agreed about the for incremental delay retirement age policy, for these older people who have the ability and the energy to continue to work, the delay retirement will make the elderly continue to use their talents and relief some of the pressure on children and can create more wealth, which has certain feasibility.

\subsection{The Incremental Advantage of Gradual Delay Retirement Age Policy}

Delay retirement age policy is not a policy of immediacy, must according to the reality after detailed study then could to take further measures, its decision-making process must be more stage and optimal. To this end, incremental will become the preferred for countries to delay retirement. Progressive is similar to the "dynamic process model of" enterprise management, divide the problem into some connection problem, and then solved respectively. In the retirement age, the time as the important node, in the progressive the issue use multi-stage sequential decision making. This decision making can not only avoid the lather about imply the delay retirement age policy implementation too quickly, but also can effectively solve the problem of an aging population payment empty, it has unique advantage of "progressive".

\section{The Gradual Delay Retirement Age Are Faced with the Difficulty and Controversial}

Delay retirement age policy taken by most countries in the world to ease the population aging. Faced with the accelerating aging, we need to establish relevant policies. But our countries delay retirement age is still discussed in research so far and it also didn't really become a system. but other people have opposite opinion, Some people in support of the incremental delay retirement age at the same time, so it faced with many difficulties and controversy.

\subsection{Delay Retirement Age Would Crowding Out Young People's Job}

The biggest opposition to delay retirement age to is that delay retirement can produce huge impact on employment, many people think that delay the retirement age crowd out of the station which belongs to the youth and burden the 
youth employment pressure. At the same time, the working population increased again after delay retirement, under the condition of the labor supply of a certain will inevitably lead to unemployment, especially to young people, which will not only lead to a lot of labor into the social, resulting in a surplus of labor conditions, at the same time have a bad effect on the stability of society. However, the community also has a part of people hold a different view, they think that delay the retirement age does not necessarily cause crowding out effect on youth employment, because the most elderly people who delayed retirement is still full of energy and desire to work, they are the main force to create the economic increase, and by the employment elasticity theory, economic growth in the long term will create more jobs, promote employment promotion, and this part of jobs the economy pull also focused on young people's jobs. From a long-term perspective, this view also has some persuasion.

\subsection{Think that Delaying Retirement Will Have a Certain Impact on the Productivity of Social Labor}

Delay retirement although can give those who are older but still contribute to work a job opportunities, but also exist the due to delay retirement and stay in position but not in the normal energy to participate in the work. At the same time, the emergence and development of the improvement of the labor productivity cannot do without new tools, and new instruments are mostly belongs to the young people"s working field, so the elderly occupy youth jobs will inevitably block new instruments to a certain extent, thus impeding the labor productivity.

\subsection{The Job Wages and Pensions Down Causing Some People to Delay Difference}

At present in our country, the worker's wage level is not high, the vast majority of workers have low wages. So there will be such a phenomenon, that is, a person's job wage below their pensions after retirement, so inevitably this class would argue for early retirement but not delay retirement. During the working time, although they pay sweat and time, but they are getting paid only a few part of pension after retirement, and they receive more than their on-the-job wage. In this way, they will naturally choose comfortable leisure and can obtain higher security retirement and is not willing to stay on the job with a low amount of wages.

\subsection{During Working Time, The Non Normal Sense of Labor Make Some People Reject to Continue to Work}

Opponents of the delayed retirement are still such person, although they took the attractive salary, but in fact the labor time has far exceeded its salary level corresponding to the workload. Their work time is not eight hours a day, but ten hours or more, at the same time, they do tired, dirty work, long-term weariness let them develop a psychological inertia, they will think that it is good to not work than to work. They don't want to continue the job will strongly hindered delay retirement age policy.

\section{Incremental Delay Retirement Age Policy}

The incremental delay retirement age policy is an important step in the reform of the endowment insurance series in China, how to walk, how to take this step will become the key. Therefore, it is very important to explore the route choice and find out effectively about progressive delay retirement age policy.

\subsection{The Proper Propaganda and Promoting Gradual Delay Retirement Policy}

Choose to progressive reform on delay retirement has been cleared at the beginning of agenda progressive here contains the following several aspects: first, about the time it is not a year or two years to complete, this policy must carry out appropriate publicity about delay the retirement age policy, make all social groups to understand or support the policy arrangement. Secondly, the sequential flexible decision, according to the specific circumstance step by step, that is analysis and discussion, then make the final decision. Once again, the retirement age delay must divide into some steps, namely the delayed project into each small step, with a smooth transition to imply the policy in the long time. Finally, promoting gradual delay retirement age policy requires top design and deal with the matters specifically related to the simultaneous treatment, so as to avoid the adverse situation of care for this and lose that. Each step here need progressive forward, and also needs proper propaganda, which send a notice to the social group in advance, so that to better implement the policy in the future .

\subsection{The Establishment of Incentive Mechanism, and Encourage Workers to Delay Retirement}

Because a large part of people still don't agree to delay the retirement age at present, then to continue to delay the retirement age policy advancement, needs to set up the encourage mechanism, help the workers just quickly understand and support this policy. Laborers to be engaged in different industries have different views on the delayed retirement age, some people think that engaged in the mental labor personnel should be delayed, because of its initial investment in a long time, but short working time, so that natural energy wisdom is not behind. As for the workers engaged in manual labor especially heavy physical strength, should not increase their burden, this part also naturally 
became hinder the power delay retirement age policy. However, in order to better carry out this policy, you must use the incentive mechanism to the opponents of certain incentives, and encourage workers to delay retirement.

\subsection{The Strict Standard Labor Time and the Implementation of the Relevant Provisions}

In China the problem of surplus labor in one part of the reason is that our country does not regulate the labor time. In many enterprises, business owners in order to enhance corporate profits, they continue to require employees to work overtime. More than 8 hours of work a day universal existence, at the same time, the existence of "one and many job" phenomenon and in part of the enterprise. This has caused a lot of the carefree position occupy, and many workers should on-the-job but being squeezed out of the labor market, which leads to the surplus labor force and job supply situation. Therefore, in strict accordance with international practices to standardize labor time in China is the key to relieve the employment pressure, the employment pressure once eased, delay the retirement age policy ahead of the road will be more easily. Therefore, the law enforcement departments must strictly review the labor supervision units for the implementation of relevant provisions of the retirement, restrain the early retirement a false retirement phenomenon.

\subsection{Scientifically Determine the Pension Standard and the Specific Reform Scheme}

The implementation of delayed retirement age policy cannot do without the age of retirement and pension standard. The combination of fairness and efficiency of the pension standard, there are two basic frame of reference: one is the retirees pension level equal to the on-the-job personnel wages and have a proper percentage two, the pensions and on-the-job index of lifelong wage levels or index of lifelong fees should have an appropriate proportion. at the same time, there should be a specific delay scheme, here are the following suggestions: First, separating men and women to delay retirement. The male retirement age in China is 60 years old, female workers 50 years of age, female cadres at the age of 55. With the development of economy and society, women's life is prolonged greatly, and should therefore be considered retirement age for men and women synchronization. If the female is divided into 15 years of delay to 65 years of age, female workers that delay one year old female cadres delay to years, every three years, as for men, divided into 10 years, until 65, and delay one year every two years old. Second, the implementation of a flexible retirement system. Elastic retirement system refers to the laborers in later reach the statutory minimum retirement age, can choose to stop working and start pension time. in this system, the delineation of the full pension eligibility age (i.e. the minimum statutory retirement age) and late forced retirement age, not retiring before the full pension eligibility age, nor a full pension, after this age and at latest forced retirement age, can choose to continue to work and receive part of the pensions, until officially retired and receive the full pension. Third, can be adjusted according to the certain position of social employment situation of the retirement age, also can give some self adjust power, truly suit one's measures to local conditions and strengthens. Such as in Shanghai City, the establishment of the pilot, according to different industries and different positions, and properly adjust the retirement age. But pension should be paid according to their job nature consistent.

\section{References}

Chen Yonghuai, \& Zhang Youpeng. (2014). On China progressive delay retirement age policy of 4th International Conference on Applied Social Science (ICASS2014), 471-476.

Li Fujun, \& Meng Xuduo. (2014). Analyof delay effect. Northwest Population retired, 35(02), 17-20.

Li Qing. (2014). Studies at the progressive delay retirement policy. GUI Hai series, 30(02), 122-125.

Liu Hongjuan. (2014). Suggested teaching - reform of the retirement age of international experience and policy plight in the reality. The ideological and political course, (02), 25-28.

Liu Zhuo, \& Li Jiguang. (2014). The purpose and difficulty of delaying retirement. Implementation of Daqing social science, (01), 25-27. 